\title{
Increasing the amylose content of durum wheat through silencing of the SBElla genes
}

\author{
Francesco Sestili', Michela Janni', Angela Doherty², Ermelinda Botticella' ${ }^{1}$, Renato D'Ovidio ${ }^{1}$, Stefania Masci', \\ Huw D Jones ${ }^{2}$ and Domenico Lafiandra*1
}

\begin{abstract}
Background: High amylose starch has attracted particular interest because of its correlation with the amount of Resistant Starch (RS) in food. RS plays a role similar to fibre with beneficial effects for human health, providing protection from several diseases such as colon cancer, diabetes, obesity, osteoporosis and cardiovascular diseases. Amylose content can be modified by a targeted manipulation of the starch biosynthetic pathway. In particular, the inactivation of the enzymes involved in amylopectin synthesis can lead to the increase of amylose content. In this work, genes encoding starch branching enzymes of class II (SBElla) were silenced using the RNA interference (RNAi) technique in two cultivars of durum wheat, using two different methods of transformation (biolistic and Agrobacterium). Expression of RNAi transcripts was targeted to the seed endosperm using a tissue-specific promoter.

Results: Amylose content was markedly increased in the durum wheat transgenic lines exhibiting SBEIla gene silencing. Moreover the starch granules in these lines were deformed, possessing an irregular and deflated shape and being smaller than those present in the untransformed controls. Two novel granule bound proteins, identified by SDSPAGE in SBElla RNAi lines, were investigated by mass spectrometry and shown to have strong homologies to the waxy proteins. RVA analysis showed new pasting properties associated with high amylose lines in comparison with untransformed controls. Finally, pleiotropic effects on other starch genes were found by semi-quantitative and RealTime reverse transcription-polymerase chain reaction (RT-PCR).

Conclusion: We have found that the silencing of SBElla genes in durum wheat causes obvious alterations in granule morphology and starch composition, leading to high amylose wheat. Results obtained with two different methods of transformation and in two durum wheat cultivars were comparable.
\end{abstract}

\section{Background}

Cereal grains contain a good balance of proteins, fats, carbohydrate, vitamins and minerals required for human growth and health. Unlike other cereals, wheat is rarely consumed in an unprocessed form but prepared into a wide range of end products. Common wheat (Triticum aestivum L.) is used in the preparation of bread, noodles, biscuits, and cakes. Durum wheat (T. turgidum L. var. durum) is used mainly for pasta production but also in an array of other regional foods in Italy, North Africa and West Asia (bread, cous cous, burghoul etc). The processing and end-use quality of wheat-based products depends on different factors such as protein content and composi-

\footnotetext{
*Correspondence: lafiandr@unitus.it

1 University of Tuscia, Department of Agrobiology \& Agrochemistry, Viterbo, Italy

Full list of author information is available at the end of the article
}

tion, grain hardness and starch composition. Starch, the most important polysaccharide in human diet and is the major component of the wheat kernel, representing more than $70 \%$ of its dry weight. As well as its importance in the food industry, starch is also used as a raw material for the production of non-food products in the paper, plastic, adhesive, textile, medical and pharmaceutical industries [1].

Reserve starch is accumulated in the amyloplast organelles and is composed of two different glucosidic polymers, amylose and amylopectin. The main differences between these polymers are the degree of polymerization and the number of side branches. Amylose is a linear chain of D-glucose molecules with a low degree of polymerization $\left(<10^{4}\right.$ units), whereas amylopectin shows a higher degree of polymerization $\left(10^{5}-10^{6}\right.$ units $)$ and which has important implications for function. Amylo- 
pectin is the major constituent of starch in wheat endosperm and comprises about 70-80\%; with amylose constituting the remaining 20-30\%. Amylose and amylopectin are synthesized by two different pathways having a common substrate (ADP-glucose). A granule bound starch synthase (GBSSI) is involved in amylose synthesis, whereas amylopectin is produced by the concerted action of starch synthases (SSI, SSII, SSIII), starch branching enzymes (SBEI, SBEIIa and SBEIIb) and starch debranching enzymes of isoamylase- and limit dextrinase-type (ISA and LD) $[2,3]$.

SBEs are transglycosylase enzymes that catalyze the formation of $\alpha-1,6$ linkages within the polymer by cleaving an internal alpha-1,4 linkage. In monocots, three starch branching isoforms are found: SBEI, SBEIIa and SBEIIb. In maize, rice and pea, suppression of SBEIIb leads to amylose-extender (ae) phenotype, with a very high amylose content $(>50 \%)$ [4-6], in contrast suppression of SBEI or SBEIIa has no effect on the amount of amylose [7-9]. In wheat SBEIIa and SBEIIb genes have been characterized and found to be located on the long arm of the homoeologous group 2 chromosomes [10-12]. Regina et al. [12] demonstrated that wheat SBEIIa gene is syntenic to the corresponding gene in other cereals, in contrast the $S B E I I b$ gene is not in a syntenic position. In wheat, SBEIIa is the predominant isoform present in the soluble phase of the endosperm [12], whereas in maize and rice endosperm SBEIIb is the predominant isoform involved in amylopectin biosynthesis $[13,14]$.

The role of SBEIIa and SBEIIb isoforms in bread wheat endosperm has been investigated by RNA interference technology [15]. In contrast to other cereals, the silencing of SBEIIb genes has no effect on amylose content and starch granule shape; whereas silencing of SBEIIa genes results in a strong increase in amylose content $(>70 \%)$ and granule deformation.

There is increasing interest in the manipulation of starch composition in wheat due to the recognition of its important role in food and non food applications and its uses in industry. In addition, the research is also focusing on the production of high amylose starch flours because derived foods have an increased amount of resistant starch which has been shown to have beneficial effects on human health. Resistant starch refers to the portion of starch that resists digestion in the stomach and small intestine and it can act as a substrate for microbial fermentation in the large intestine, the end-products being hydrogen, carbon dioxide, methane and short chain fatty acids (SCFA) $[16,17]$. The nutritionists believe that the resistant starch has a role similar to dietary fibre inside the intestine, protecting against diseases as colon cancer, type II diabetes, obesity and osteoporosis [17-21].

A recent study demonstrated that high-amylose flours might be used to substitute for up to $50 \%$ normal wheat flour to make bread with both an acceptable bread quality and a significantly higher amount of resistant starch [22].

Furthermore, pasta produced with semolina containing a higher amylose content shows good cooking resistance and firmness, satisfying consumer preferences [23].

In the present study, a transgenic approach was used to increase the amylose content in durum wheat seeds. In particular, the effects of SBEIIa silencing were investigated in terms of amylose content, transcript accumulation and protein profile of the enzymes involved in starch biosynthesis.

\section{Results}

Biolistic transformation and selection of transgenic plants In total, 1954 immature embryos obtained from the Triticum durum cv. Svevo were co-transformed using pRDPT + SBEIIa(RNAi) and bar selectable marker plasmids. Forty eight $\mathrm{T}_{0}$ independent transgenic lines resistant to bialaphos and containing the RNAi cassette were obtained, with a co-transformation efficiency of $2.5 \%$. The presence of the transgene was verified by polymerase chain reaction (PCR) analysis of genomic DNA from regenerated plants, by using two primer pairs, one specific for the promoter of the construct (PromDx5Fw/ PromDx5R) and another for the bar gene (BarFw/BarR), to produce amplicons of $473 \mathrm{bp}$ and $405 \mathrm{bp}$, respectively (data not shown). No significant differences in morphology and growth were observed between transgenic lines and either the corresponding "null" genotype that had lost the transgene by segregation (null segregant), or untransformed plants.

\section{Agrobacterium-mediated transformation and selection of transgenic plants}

In all, 1.759 immature embryos of the Triticum durum cv. Ofanto were transformed using pGUB-G + SBEIIa (RNAi) containing also the bar gene cassette in the T-DNA. Thirteen $\mathrm{T}_{0}$ transgenic lines were obtained with a transformation efficiency of $0.74 \%$. The presence of the transgene was verified as described above. As with transgenic plants generated by biolistic transformation, no morphological differences were observed among the different lines or between transgenics and controls.

\section{Molecular characterization of transgenic plants}

The absence of SBEIIa transcript was investigated by semiquantitive RT-PCR and Real Time RT-PCR on total RNA, extracted from $\mathrm{T}_{2}$ immature kernels (18 DPA), using a primer pair specific for SBEIIa genes (SBEIIaFw/ SBEIIaR). We focused on six transgenic lines, three derived from the biolistic method and three from Agrobacterium-mediated transformation. GADPH (glyceraldehyde 3-phosphate dehydrogenase) was used as housekeeping gene. 
A complete silencing of SBEIIa genes was observed in four lines and partial silencing in two lines (Figure 1). Both the partially silenced lines were obtained by biolistic bombardment while the three lines obtained through Agrobacterium-mediated transformation were completely silenced. In one plant (MJ16-114) the level of SBEIIa transcript was 30-fold less than in the control line, while in line MJ16-119 the expression of the target gene appeared to be unaffected at 18 DPA (Figure 2).

Starch granule-bound proteins, extracted from transgenic seeds, were separated on SDS-PAGE gel and compared with those present in the untransformed cultivars. Unexpectedly, two new starch granule-bound proteins were identified in the transformed lines (Figure 3), showing a molecular weight between 78 and $85 \mathrm{KDa}$. More-

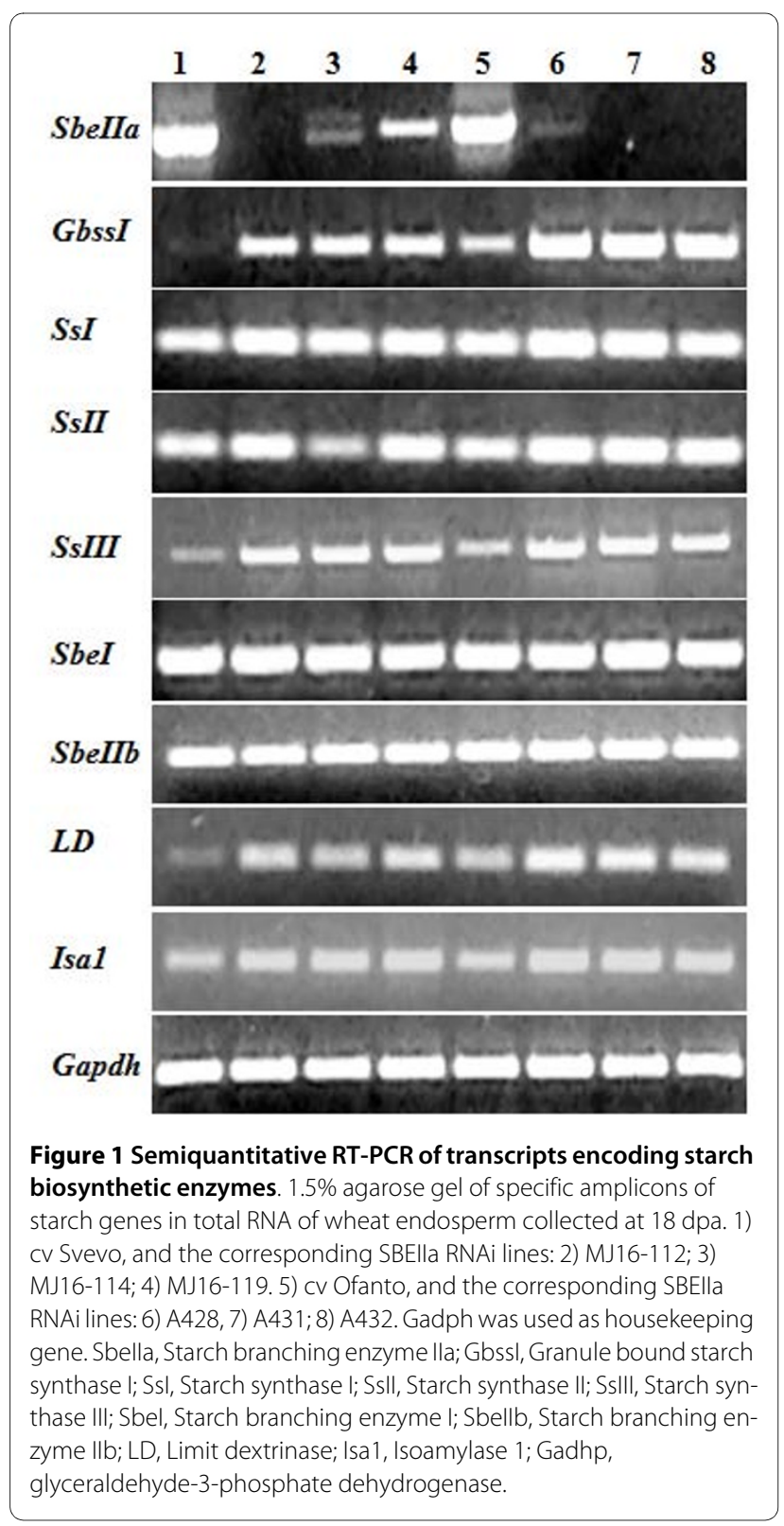

over, the intensity of SGP-3, and to a lesser extent SGP-2, SGP-1 and waxy was higher in the transgenic lines.

The two novel SGPs (SGP-4 and SGP-5) were investigated by mass spectrometry and shown to be waxy-like proteins (Table 1). SGP-4 and SGP-5 were similar to durum wheat genbank accession BAA88512 with a coverage of $41 \%$ (247/604 aa) and 36\% (215/604 aa), respectively. In both cases the probability that the two proteins corresponded to accession BAA88512 was $100 \%$.

Determination of total starch, amylose and protein content The amylose content was strongly increased in SBEIIa RNAi transgenic lines in comparison to untransformed controls of Svevo and Ofanto. Amylose values ranged from $30.8 \%$ up to $75 \%$ (Figure 4; Table 2). Although the amylose percentage was more than $70 \%$ in endosperm from the MJ16-112 line, the plant morphology, shape and yield of seeds (Table 2) was not significantly different from non-transformed controls. A reduction in the endosperm starch content of transgenic lines obtained by biolistic transformation was observed (Table 2). The protein content of the same lines ranged between $16.16 \%$ and $18.95 \%$ and were similar to untransformed control (18.36\%) (Table 2).

\section{Starch granule analysis}

SEM analysis showed deep alterations of starch granules in MJ16-112 line. The granules with reduced SBEIIa expression were deformed with irregular shape, looked deflated and were smaller than wild type (Figure 5). In particular, a high number of A-type granules had a size of $10 \mu \mathrm{m}$ and B-type granules had lost the spherical shape typical of the controls (Figure 5). This phenotype was observed both in Svevo and Ofanto transgenic lines and is clearly visible in Figure 5. Deformation of starch granules was more evident in line MJ16-112 compared to A432, this could be associated to the different level of amylose content existing between the two lines.

\section{RVA analysis}

Viscosity properties of whole wheat flours were measured by the Rapid Visco Analyser (RVA) on Svevo and the silenced lines MJ16-112 and MJ16-114. In the case of the high-amylose lines, an overall decrease in viscosity was observed in comparison with the non-transgenic line (cv Svevo). Significant variations were observed for all RVA parameters. Mean trough (TG), breakdown (BD), setback (SB) and final viscosities (FV) of SBEIIa silenced lines were significantly lower than for the control wheat samples (Figure 6; Table 3). There was a clear difference in the retrogradation rates of starches between Svevo and the corresponding transgenic lines, MJ16-112 and MJ16-114. Even though SBEIIa RNAi lines had high amylose content, the setback value was smaller than the control, sug- 


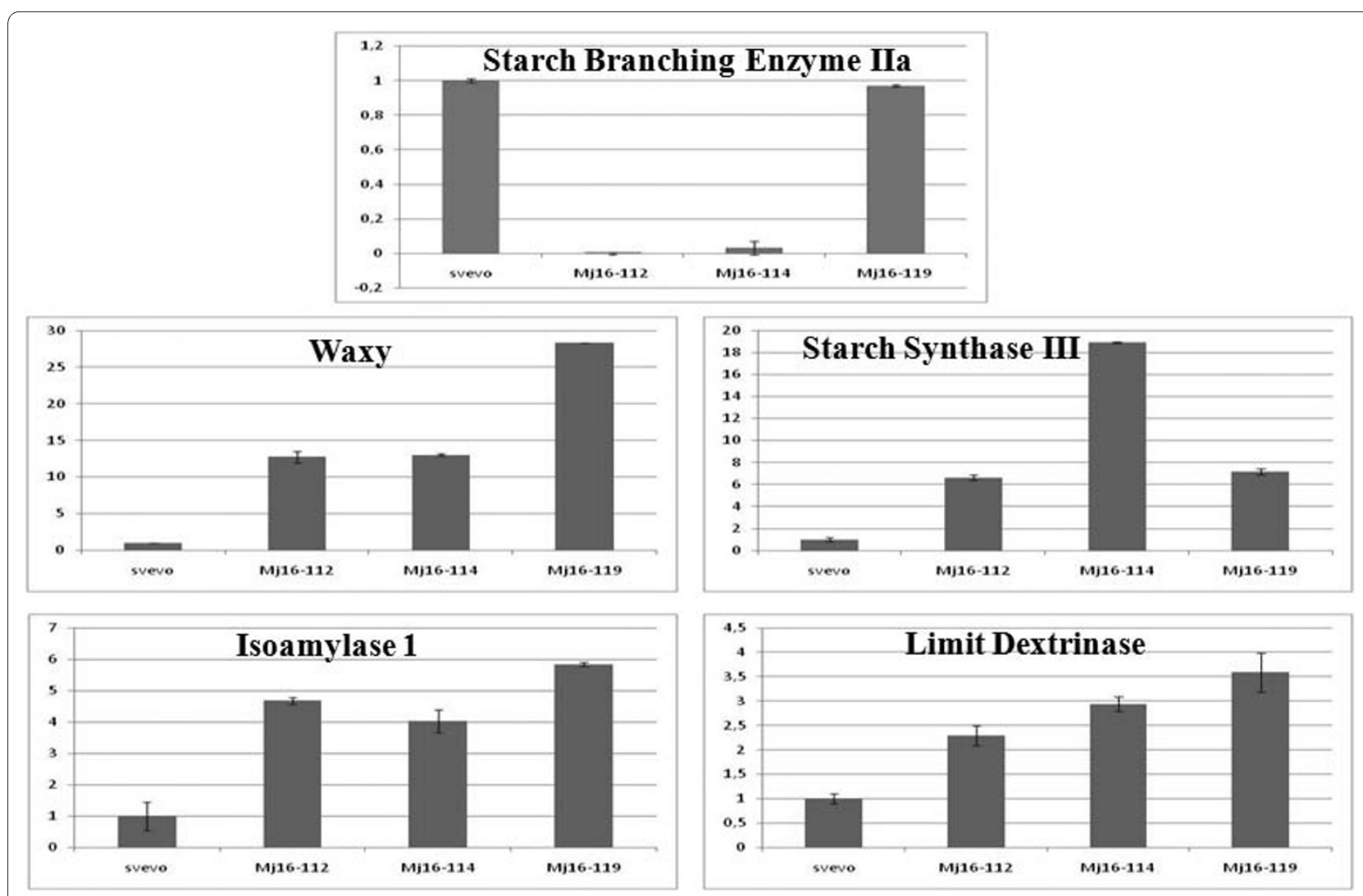

Figure 2 Real Time quantitative RT-PCR analysis of SBEIIa, GBSSI, SSIII, LD and ISA1 genes. Transcript levels were evaluated on cDNA obtained from total RNA of immature seeds (18 dpa). The analysis were performed on cv Svevo and the corresponding SBEIla RNAi lines MJ16-112, MJ16-114 and MJ16-119.

gesting that a lower retrogradation of these RNAi lines is due to their lower viscosity value. We observed a negative correlation between amylose percentage and viscosity; in particular the line MJ16-112 had the higher amylose content $(75 \%)$ and the lower viscosity values. Whereas the line MJ16-114, possessing 43.5\% of amylose, had a intermediate RVA profile compared to Svevo and MJ16-112.

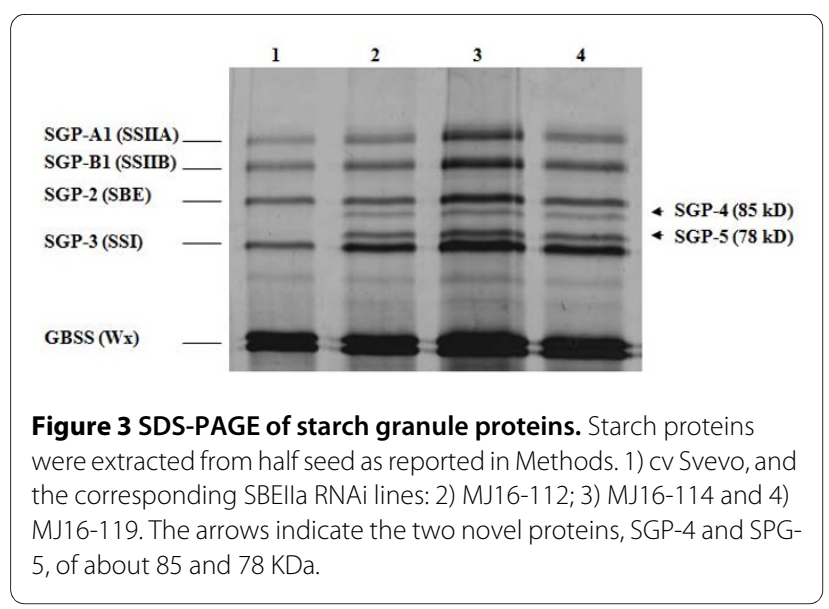

Real Time RT-PCR on genes involved in starch biosynthesis

To understand if there were pleiotropic effects on the expression of other genes involved in starch biosynthesis, semiquantitative RT-PCR was performed on GBSSI, SSI, SSII, SSIII, SBEI, SBEIIb, ISA 1 and $L D$ genes. The expression levels of many starch biosynthetic genes were affected by the silencing of SBEIIa genes. Compared to the control lines, the transcripts of the genes encoding GBSSI, SSIII, LD and ISA1 were increased in transgenic plants, whereas significant changes were not found in $S S I$, SSII, SBEI and SBEIIb genes.

Transcript accumulation of GBSSI, SSIII, LD and ISAI were investigated by quantitative Real-Time RT-PCR. As expected, all analyzed genes were up-regulated in comparison with untransformed plants but their level of upregulation varied (Figure 2). The expression of GBSSI was strongly increased in transgenic seeds with a 12-28 fold increase compared to controls). The expression of SSIII, $L D$ and $I S A 1$ was up-regulated by $6-18,1,5-3,5$ and $4-6$ fold respectively in Svevo transgenic plants compared to controls (Figure 2). 
Table 1: Peptides identified by mass-mass spectrometry on SGP-4 and SGP-5 proteins.

\begin{tabular}{|c|c|c|c|c|}
\hline Peptide $\mathbf{N}^{\circ}$ & Actual mass (MH+) & Theor mass (MH+) & From-To & Sequence \\
\hline \multicolumn{5}{|l|}{ SGP-4 } \\
\hline 1 & 814.29 & 815.46 & $304-311$ & $\mathrm{~K}>\mathrm{AGILQADK}<\mathrm{V}$ \\
\hline 2 & 1443.8 & 1443.80 & $39-52$ & A $>$ ALVMRTIGASAAPK $<Q$ \\
\hline 3 & 1348.47 & 1349.66 & $125-136$ & $\mathrm{~K}>$ DAWDTSVVSEIK $<\mathrm{V}$ \\
\hline 4 & 1395.82 & 1396.74 & $380-392$ & $\mathrm{~K}>\mathrm{EALQAEVGLPVDR}<\mathrm{K}$ \\
\hline 5 & 1564.04 & 1564.76 & $479-491$ & $\mathrm{R}>\mathrm{FEPCGLIQLQGMR}<\mathrm{Y}$ \\
\hline 6 & 2231.62 & 2232.09 & $458-478$ & $\mathrm{R}>\mathrm{FNAPLAHQMMAGADVLAVTSR}<\mathrm{F}$ \\
\hline 7 & 1685.30 & 1684.80 & $266-279$ & $\mathrm{R}>\mathrm{FSFDDFAQLNLPDR}<\mathrm{F}$ \\
\hline 8 & 1477.29 & 1476.75 & $192-204$ & $\mathrm{R}>\mathrm{FSLLCQAALEAPR}<\mathrm{I}$ \\
\hline 9 & 1483.91 & 1482.82 & $408-421$ & K>GPDVMIAAIPEILK<E \\
\hline 10 & 1827.14 & 1826.82 & $176-191$ & $\mathrm{~K}>$ IYGPDAGTD YEDNQLR<F \\
\hline 11 & 3494.18 & 3492.88 & $403-434$ & R>LEEQKGPDVMIAAIPEILKEEDVQIVLLGTGK $<K$ \\
\hline 12 & 1545.07 & 1544.76 & $520-533$ & $\mathrm{R}>\mathrm{LSVDCNVVEPADVK}<\mathrm{K}$ \\
\hline 13 & 1672.88 & 1672.86 & $520-534$ & $\mathrm{R}>$ LSVDCNVVEPADVKK $<\mathrm{V}$ \\
\hline 14 & 1831.94 & 1831.85 & $282-297$ & $\mathrm{~K}>\mathrm{SSFDFIDGYDKPVEGR<K}$ \\
\hline 15 & 821.07 & 821.37 & $513-519$ & $\mathrm{~K}>\mathrm{TGFHMGR<L}$ \\
\hline 16 & 1977.70 & 1977.98 & $92-112$ & $\mathrm{~K}>\mathrm{TGGLGDVLGGLPPAMAANGHR<V}$ \\
\hline 17 & 881.01 & 881.40 & $137-143$ & $\mathrm{~K}>\mathrm{VADEYER}<\mathrm{V}$ \\
\hline 18 & 1997.26 & 1997.02 & $312-329$ & $\mathrm{~K}>\mathrm{VLTVSPYYAEELISGEAR<G}$ \\
\hline 19 & 815.84 & 816.53 & $535-541$ & $\mathrm{~K}>\mathrm{VVTTLKR}<\mathrm{A}$ \\
\hline \multicolumn{5}{|l|}{ SGP-5 } \\
\hline 1 & 814.5 & 815.46 & $304-311$ & $K>A G I L Q A D K<V$ \\
\hline 2 & 1348.95 & 1349.66 & $125-136$ & $\mathrm{~K}>\mathrm{DAWDTSVVS}$ EIK $<\mathrm{V}$ \\
\hline 3 & 1395.62 & 1396.74 & $380-392$ & $\mathrm{~K}>\mathrm{EALQAEVGLPVDR}<\mathrm{K}$ \\
\hline 4 & 2214.29 & 2213.11 & $186-204$ & $Y>$ EDNQLRFSLLCQAALEAPR<I \\
\hline 5 & 2084.28 & 2083.96 & 174-191 & $\mathrm{K}>$ EKIYGPDAGTD YEDNQLR<F \\
\hline 6 & 1564.24 & 1564.76 & $479-491$ & $\mathrm{R}>\mathrm{FEPCGLIQLQGMR<Y}$ \\
\hline 7 & 2231.58 & 2232.09 & $458-478$ & $\mathrm{R}>\mathrm{FNAPLAHQMMAGADVLAVTSR<F}$ \\
\hline 8 & 1476.17 & 1476.75 & $192-204$ & $\mathrm{R}>\mathrm{FSLLCQAALEAPR}<\mathrm{I}$ \\
\hline 9 & 1123.02 & 1123.49 & $330-338$ & $\mathrm{R}>\mathrm{GCELDNIMR}<\mathrm{L}$ \\
\hline 10 & 1826.08 & 1826.82 & $176-191$ & $\mathrm{~K}>$ IYGPDAGTDYEDNQLR<F \\
\hline 11 & 1099.04 & 1099.70 & $393-402$ & $\mathrm{R}>\mathrm{KVPLV}$ AFIGR $<\mathrm{L}$ \\
\hline 12 & 1545.25 & 1544.76 & $520-533$ & $\mathrm{R}>$ LSVDCNVVEPADVK $<\mathrm{K}$ \\
\hline 13 & 1673.51 & 1672.86 & $520-534$ & $\mathrm{R}>\mathrm{LSVDCNVVEPADVKK}<\mathrm{V}$ \\
\hline 14 & 1831.15 & 1831.85 & $282-297$ & $\mathrm{~K}>\mathrm{SSFDFIDGYDKPVEGR<K}$ \\
\hline 15 & 1979.22 & 1977.98 & $92-112$ & $\mathrm{~K}>\mathrm{TGGLGDVLGGLPPAMAANGHR<V}$ \\
\hline 16 & 1996.44 & 1997.02 & $312-329$ & $\mathrm{~K}>\mathrm{VLTVSPYYAEELISGEAR<G}$ \\
\hline 17 & 815.4 & 816.53 & $535-541$ & $\mathrm{~K}>\mathrm{VVTTLKR}<\mathrm{A}$ \\
\hline 18 & 1236.44 & 1237.61 & $319-329$ & $\mathrm{Y}>\mathrm{YAEELISGEAR<G}$ \\
\hline 19 & 2155.20 & 2156.00 & $492-512$ & $\mathrm{R}>\mathrm{YGTPCACASTGGLVDTIVEGK}<\mathrm{T}$ \\
\hline
\end{tabular}




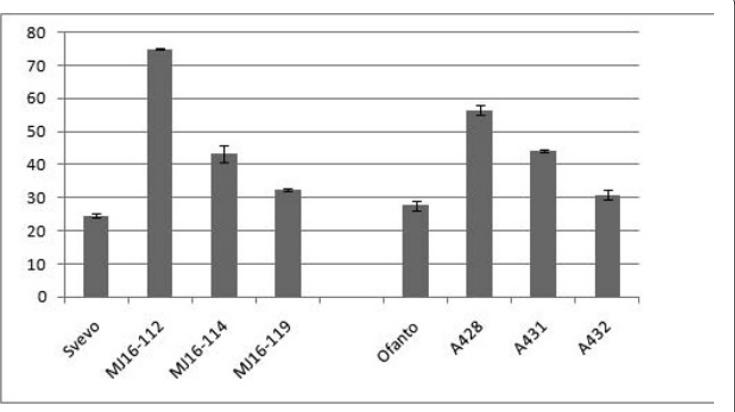

Figure 4 Amylose content of SBElla RNAi lines and untransformed cultivars (cv Svevo and cv Ofanto). MJ16-112, MJ16-114 and MJ16-119 correspond to transgenic lines obtained from particle bombardment of cv Svevo; A428, A431 and A432 transgenic lines derived from Agrobacterium-mediated transformation of cv Ofanto.

\section{Discussion}

Different strategies can be used to modify amylose content in wheat starch. In the last twenty years the identification of null mutations in starch biosynthetic genes and the crossing of these materials to combine functional mutations have permitted the production of lines with low and high amylose content [24-26]. Unfortunately this strategy is not easy to apply for all starch biosynthetic proteins, due to the difficulty of obtaining the relevant mutants in polyploid species such as wheat.

Both transgenic and non-transgenic tools are available, and the latter, along with novel technologies, offers the possibility to manipulate starch composition and develop wheat varieties with new functionalities. Recently a reverse genetic strategy called TILLING (Target Induced Local Lesions in Genomes) has permitted the identification of induced mutations for genes involved in amylose [27] and amylopectin [28] biosynthesis. The TILLING strategy is an efficient, non-transgenic method to identify mutants in genes of interest, but the effect of silencing is often masked by the presence of other functional alleles in polyploid species. To obtain a null phenotype, it is usu- ally necessary to generate double or triple mutants by crossing single null genotypes [29].

Recent studies have demonstrated that transgenic technology is a powerful research tool to modify amylose/ amylopectin ratio. Starch composition can be manipulated through genetic engineering, either by overexpression or repression of starch biosynthetic genes. RNAi technology is a specific and powerful mean to silence a target gene. This technology is particularly useful in polyploid plants such as wheat because it increases the possibility to obtain transgenic plants with a novel phenotype.

In this study, an RNAi strategy has been followed to silence SBEIIa genes in order to increase the amylose content in two durum wheat cultivars, Svevo and Ofanto. Although two different methods have been used for genetic transformation (biolistic for cv Svevo and Agrobacterium for cv Ofanto), the silencing of SBEIIa genes produced similar effects. The Agrobacterium- or the biolistic-mediated genetic transformation showed various levels of silencing between independent transgenic wheat lines. The abundance of mRNAs of SBEIIa genes varied in the transgenic lines from nearly undetectable to wild type level confirming that the RNAi construct, designed to reduce the expression of SBEIIa genes, was effective in inducing gene silencing. The variation in the levels of gene silencing observed here is in agreement with previously reported results in wheat [30,31] and other species, such for example tobacco [32], maize [33] and Arabidopsis [34].

The silencing of the SBEIIa gene caused marked modifications on amylose content, granule morphology and starch composition. An increase in amylose content was found in all transgenic lines but its percentage varied between lines, presumably due to differences in copy number and/or positional effects. The line MJ16-112 showed the exceptionally high value of $75 \%$ amylose content, while in the other lines it varied between $31-56 \%$. A variable level of amylose content between RNAi lines was also found in sweetpotato [35] and potato [36].

Table 2: Seed weight, total starch, amylose and protein content of RNAi transgenic lines and control plants.

\begin{tabular}{|c|c|c|c|c|}
\hline Lines & 100 grain weight & Starch content $\%$ & Amylose content $\%$ & Protein content $\%$ \\
\hline Svevo & $4.14 \pm 0.14$ & $59.80 \pm 0.10$ & $24.50 \pm 0.70$ & $18.36 \pm 0.13$ \\
\hline MJ16-112 & $3.90 \pm 0.12$ & $50.98 \pm 0.68$ & $75.05 \pm 0.36$ & $18.95 \pm 0.36$ \\
\hline MJ16-114 & $3.74 \pm 0.10$ & $44.91 \pm 2.36$ & $43.50 \pm 2.52$ & $16.16 \pm 0.30$ \\
\hline MJ16-119 & $4.06 \pm 0.22$ & $45.17 \pm 1.47$ & $32.40 \pm 0.39$ & $17.38 \pm 0.16$ \\
\hline Ofanto & nd & nd & $27.69 \pm 1.49$ & nd \\
\hline A428 & nd & nd & $56.44 \pm 1.43$ & nd \\
\hline A431 & nd & nd & $44.25 \pm 0.46$ & nd \\
\hline A432 & nd & nd & $30.87 \pm 1.52$ & nd \\
\hline
\end{tabular}

Values represent means of three replicates. Standard error is also reported for each value. Nd: not determined. 

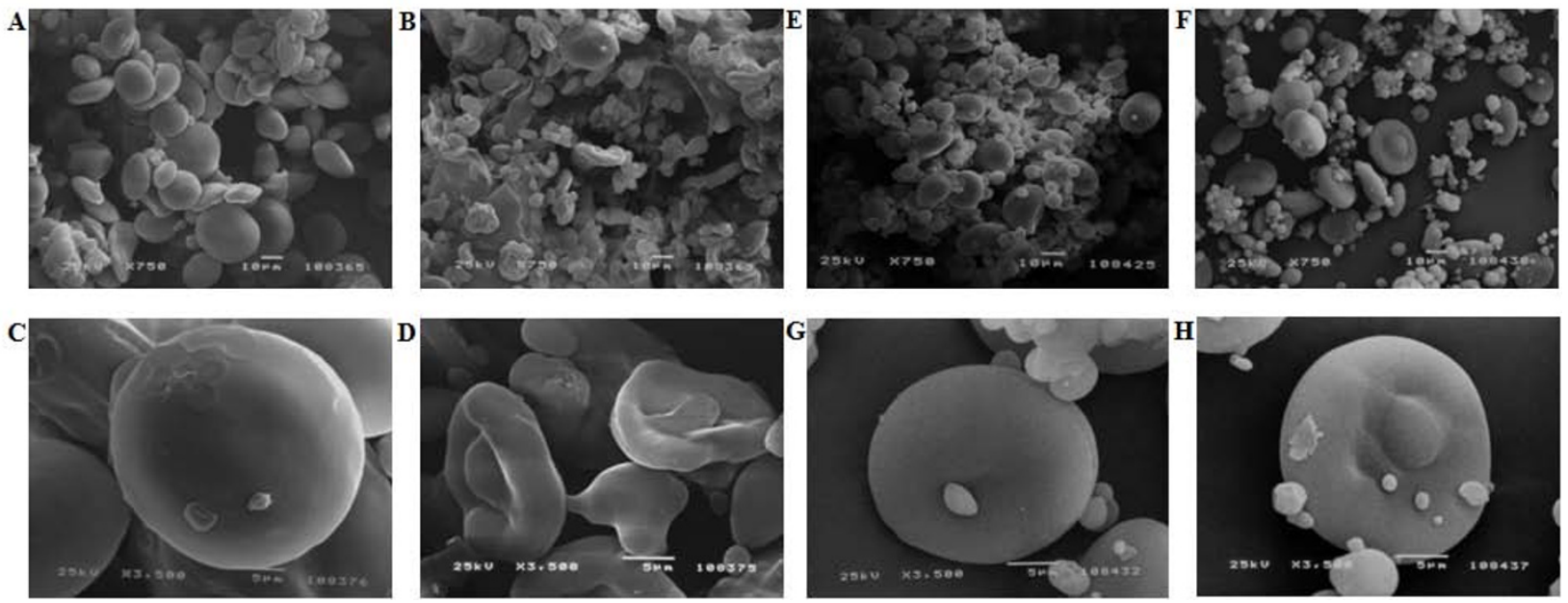

Figure 5 Scanning electron micrographs of isolated starch granules. A) and C) nontransformed control wheat cv Svevo; B) and D) SBElla RNAi MJ16-112 line; E) and G) nontransformed control wheat cv Ofanto; F) and H) SBElla RNAi A432 line.

No significant difference was observed in grain yield between transformed and control lines, although RNAi lines showed a lower total starch content. The reduction of total starch in RNAi lines could be due to the difficulty to estimate starch content in high amylose wheats. McClearly et al. [37] used different approaches to determine total starch content and found that in high amylose maize the starch content resulted always underestimated.

Morphological analysis of starch granules showed a marked difference between SBEIIa-silenced lines and control plants. Type-A granules appeared smaller and deflated, whereas type-B granules lost their normal spherical shape and became extended. Similar results were obtained by Regina et al. [15] who suppressed the activity of SBEIIa through RNAi technology in bread wheat.

RVA analysis, carried out on whole wheat flour, highlighted large alterations in chemical-physical properties of transgenic starch. RVA parameters, as mean trough, breakdown, setback and final viscosities of SBEIIa-

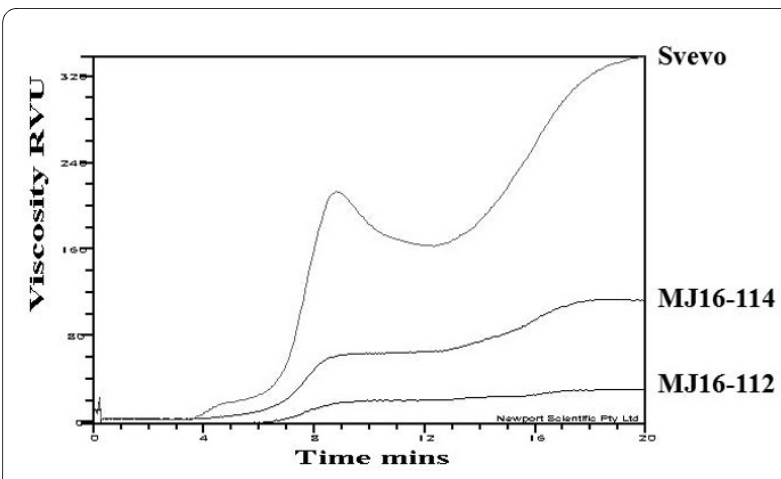

Figure 6 RVA viscograms of control (Svevo) and SBElla-RNAi lines (MJ16-112 and MJ16-114) whole wheat flours. silenced lines, were significantly lower than normal wheats. These results are consistent with those obtained on high amylose flour of wheat [38], corn [39] and barley [40]. The decreased swelling and viscosity affects chemical-physical pasting properties of semolina, with subsequent changes in functional characteristics of derived food products. Although high amylose flour resulted in a smaller bread loaf volume [41], it has a positive impact in the pasta industry, reducing starch loss during the cooking and increasing pasta firmness. In addition, high amylose foods might have beneficial effects on human diet because of an increased amount of resistant starch, which has a role similar to dietary fibre inside the intestine, protecting against diseases as colon cancer, type II diabetes, obesity and osteoporosis $[17,18]$.

SDS-PAGE analysis of starch granule-bound proteins allowed the identification of two newly accumulated proteins localized between the SGP-2 and SGP-3 in the transgenic lines. These novel proteins are present in all transgenic plants, suggesting that they are a consistent result of SBEIIa silencing rather than an unintended effect of random transgene insertions. The novel proteins show a high similarity to the waxy isoforms. Since the molecular mass of the novel proteins is larger ( 85 and 78 $\mathrm{KDa}$ ) than that of waxy proteins $(58-60 \mathrm{KDa})$, one possibility is that the novel proteins are encoded by genes that are poorly or not expressed in wild type cultivar. An alternative explanation is that a mechanism of post-translation modification has somehow been triggered in these transgenic lines.

The staining intensity of the other starch granule proteins (SGP-140, SGP-145, SGP-1, SGP-3 and waxy) on SDS-PAGE is strongly increased in the silenced lines compared to the control. Real-Time RT-PCR analyses on 
Table 3: RVA parameters of durum wheat cultivar Svevo and RNAi transgenic lines (MJ16-112 and MJ16-114).

\begin{tabular}{cccccc}
\hline Sample & PV & BD & FV & SB & PT \\
\hline Svevo & 213,66 & 50,5 & 338 & 174,83 & 8,79 \\
MJ16-112 & 20,25 & 2,1 & 29,1 & 11 & 9,93 \\
MJ16-114 & 64,16 & 1,58 & 113,41 & 50,83 & 9,99 \\
\hline
\end{tabular}

PV, peak viscosity; BD, breakdown; FV, final viscosity; SB, setback; PT, peak time.

genes involved in starch biosynthesis have confirmed possible interaction and feedback mechanisms between these genes. In particular, the absence of SBEIIa isoforms leads to an up-regulation of $W x, S S I I I, L D$ and ISAI genes.

Pleiotropic effects associated with up-regulation or suppression of specific genes present in the starch biosynthetic pathway have been reported previously. For example, Kosar-Hashemi et al. [42] observed a reduction of granule-bound branching enzymes and starch synthases in the starch granule of the SSII mutants and suggested that the lack of SSII would lead to the absence of the complex on starch granule. Similarly, the rice sugary1 (null for isoamylase) and the maize dull-1 (not expressing SSIII) mutants had drastic changes in accumulation of pullulanase and SBEIIb isoforms, respectively $[43,44]$. In a recent work, the down-regulation of a pullulanase-type DBE inhibitor produced pleiotropic effects on activities of soluble and granule-bound starch synthase, that were significantly reduced [45]. Tetlow et al. [46] have discovered the formation of a heterocomplex comprising SBEI, SBEIIb, and starch phosphorylase in wheat. More recently, Tetlow et al. [47] have identified trimeric assemblages of SSI with SSIIa and either SBEIIa or SBEIIb. Hennen-Bierwagen et al. $[48,49]$ have demonstrated that SSs, SBEs and DBEs associate physically with each other in multisubunit complexes and the lack of one subunit can cause variation on the other isoforms. In maize the $a e^{-}$ mutation, in the gene coding for SBEIIb, was associated with the detection of four novel proteins not observed in wild-type granules. LC-MS/MS analysis showed that the four bands corresponded to SBEI, SBEIIa, SSIII and starch phosphorylase [50]. Grimaud et al. [50] suggested that structural changes in amylopectin, due to the loss of SBEIIb, could offer a more efficient glucan substrate for binding of SBEI, SBEIIa, starch phosphorylase and SSIII. The pleiotropic effects observed in our SBEIIa-silenced lines represent additional evidence of a strict correlation between all starch enzymes and that the lack of one subunit can cause variation in the other isoforms.

\section{Conclusions}

The RNAi-mediated down-regulation of genes coding the SBEIIa isoforms produced remarkable changes in starch chemical-physical properties of durum wheat. No significant differences were identified in grain weight between transgenic plants and wild type controls. As well as a considerable increase in the amylose content, the silenced SBEIIa wheat lines also possessed altered starch granule structure and up-regulated transcriptional profiles of GBSSI, SSIII, LD and ISA1. The use of two different transformation methods, biolistic and Agrobacteriummediated, and two different durum wheat cultivars, highlights that the effect of SBEIIa silencing on starch metabolism is genotype and protocol independent because similar effects have been detected in all the RNAi plants obtained.

The variation in amylose content and the different starch physical-chemical properties make these plant materials particularly valuable in a vast range of applications in both food and non food industries.

\section{Methods}

\section{Plant material}

Durum wheat plants (cv Svevo and cv Ofanto) were vernalized at $4{ }^{\circ} \mathrm{C}$ for one month and grown in a growth chamber at $20 / 18^{\circ} \mathrm{C}$ day/night temperature under a $16 / 8$ $\mathrm{h}$ photoperiod.

\section{Vectors for biolistic and Agrobacterium-mediated transformation}

The first three exons, of the wheat SBEIIa gene were amplified by RT-PCR on total RNA extracted from immature seeds (18 dpa), while the third intron of the wheat SBEIIa gene was amplified from genomic DNA of Svevo. The primers used were: SalIXbaISBEII(cDNA)FW 5'-gtcgactctagaggcgggttgagtgagatctg; KpnIXhoISBEII(cDNA)R $\quad 5$ '-ggtaccctcgagtcggtagtcaagatggctcc; SalIKpnISBEII(INT)FW 5'-gtcgacggtaccgcagaaaatatacgagattg; XbaIXhoISBEII(INT)R 5'-acctctagactcgagccaccttcatgttggtcaatag.

cDNA synthesis was performed by using the QuantiTect Reverse Transcrition Kit (Qiagen) following the manufacturer instructions.

PCR reactions were carried out in $50 \mu \mathrm{l}$ final volume using 50-100 ng of genomic DNA or $1 \mu \mathrm{l}$ of cDNA, 2.5 units of FastStart High Fidelity PCR system (Roche Diagnostics), $1 \times$ Taq PCR buffer, $50 \mathrm{ng}$ of each of the two 
primers and $100 \mu \mathrm{M}$ of each deoxyribonucleotide. PCR conditions were: 1 cycle at $95^{\circ} \mathrm{C}$ for $2 \mathrm{~min}, 35$ cycles at $95^{\circ} \mathrm{C}$ for $30 \mathrm{~s}, 60^{\circ} \mathrm{C}$ for $1 \mathrm{~min}, 72^{\circ} \mathrm{C}$ for $1 \mathrm{~min}$, and a final step at $72^{\circ} \mathrm{C}$ for $5 \mathrm{~min}$.

The intron was ligated in the vector pRDPT containing the promoter and terminator of the Dx5 high molecular weight glutenin subunit gene [51]. Then taking advantage of restriction sites introduced on the primers, the sense and antisense sequences of the target region were inserted in the plasmid pRDPT separated each one by the intron. This construct was used for biolistic transformation.

The entire cassette (promoter-sense-intron-antisenseterminator) was extracted from pRDPT vector by digestion with SmaI and HpaI restriction enzymes and cloned into the SmaI site of the vector pG-UB carrying the bar gene that confers resistance to the bialaphos herbicide under the ubiquitin promoter. This construct was used for Agrobacterium-mediated transformation.

\section{Biolistic and Agrobacterium transformation of durum wheat embryos}

For the transformation experiments, the plasmid pAHC20 [52], carrying the bar gene, was co-bombarded with pRDPT + SBEIIa(RNAi) in a 1:3 molar ratio. Constructs were introduced into immature embryos of $T$. durum cv. Svevo excised from seeds in Zadoks stage 72, using a Model PDS-1000/He Biolistic particle delivery system (Bio-Rad, Hercules, CA, U.S.A.) and the protocols described in Okubara and associates [53]. The protocol of Wu et al. [54] was used for transformation of durum wheat Ofanto by Agrobacterium. The presence of the construct in bialaphos-resistant plants and their progeny was verified by PCR on total DNA obtained from leaf sections of mature plants [55] with primer pairs specific for the promoter Dx 5 and for the bar gene (PromDx5Fw catgcaggctaccttccac, PromDx5R cggtggactatcagtgaattg, BarFw catcgagacaagcacggtca and BarR gaaacccacgtcatgccagt). T2 non segregating progeny were used for molecular and biochemical analyses (additional file 1).

PCR reactions were carried out in $50 \mu \mathrm{l}$ final volume using 50-100 ng of genomic DNA, $1 \times$ Red Taq ReadyMix PCR REACTION MIX (1.5 U Taq DNA Polymerase, 10 $\mathrm{mM}$ Tris- $\mathrm{HCl}, 50 \mathrm{mM} \mathrm{KCl}, 1.5 \mathrm{mM} \mathrm{MgCl} 2,0.001 \%$ gelatine, $0.2 \mathrm{mM} \mathrm{dNTPs}$ ) and $0.5 \mu \mathrm{M}$ of each of the two primers.

Amplification conditions included an initial denaturation step at $94^{\circ} \mathrm{C}$ for $3 \mathrm{~min}$, followed by 35 cycles at $94^{\circ} \mathrm{C}$ for $1 \mathrm{~min}, 60^{\circ} \mathrm{C}$ for $1 \mathrm{~min}$ and $72^{\circ} \mathrm{C}$ for $1 \mathrm{~min}$, followed by a final incubation at $72^{\circ} \mathrm{C}$ for $5 \mathrm{~min}$.

\section{Semiquantitative Reverse transcriptase-polymerase chain reaction}

Total RNA was extracted from immature seeds (18 DPA) as reported in Laudencia-Chingcuanco et al. [56] with some modifications. The starting material was $0.1 \mathrm{~g}$ and all volumes of buffers and solutions were diluted 1 to 10 . For reverse transcriptase-mediated PCR studies, cDNA was synthesised from $1 \mu \mathrm{g}$ of total RNA using an oligo(dT) primer and Superscript Reverse Transcriptase III (Invitrogen). One of twentieth volume of each cDNA was used as a template for PCR amplification. PCR reactions were carried out in $30 \mu \mathrm{l}$ final volume using 1 units of Ex-Taq (Takara), $1 \times$ buffer, 0,2 mM of each dNTPs, 0,5 $\mu \mathrm{M}$ of each primer. Amplification conditions included an initial denaturation step at $98^{\circ} \mathrm{C}$, followed by 35 cycles at $98^{\circ} \mathrm{C}$ for $10 \mathrm{sec}$., $58^{\circ} \mathrm{C}$ for $1 \mathrm{~min}$. and $72^{\circ} \mathrm{C}$ for $1 \mathrm{~min}$, followed by a final extension at $72^{\circ} \mathrm{C}$ for $5 \mathrm{~min}$. The following gene-specific primers were designed for GAPDH (GAPDHFw 5'-caacgctagctgcaccactaact and GAPDHR 5'gactcctccttgatagcagcctt) [57], GBSSI (Wx-B1Fw 5'cgaagcaacaaagccggaaag and Wx-B1R 5'-tcaccctctcgtactcgtccg), SSI (SSIFw 5'-agggtacagggtgggcgttct and SSIR 5'-gtagggttggtccacgaagg), SSII (SSIIFw 5'-ttcgaccccttcaaccactc and SSIIR 5'-acgtcctcgtagagcttggc), SSIII (5'ggcgttggatgtgtatatgg and 5 '-ggtgatgattccgacaatagg) [58], SBEI (SBEIFw 5'-aaacaaacttcaacaaccgcc and SBEIR 5'acctcctgtagacgcctttt), SBEIIa (SBEIIaFw 5'-tgacgaatcttggaaaatgg and SBEIIaR 5'-ggcggcatttatcataactattg), SBEIIb (SBEIIbFw 5'-gtagatgcggtcgtttacttga and SBEIIbR 5'-ccagccaccttctgtttgtt), LD (LDFw 5'-tatgagtggaacagggattggt and LDR 5'-atttggtcagcgtaagtagcg) and ISA1 (ISA1Fw 5'aagatgaaagacagggcgagat and ISA1R 5'-aatactaggatgaccgatgagtagct).

\section{Real-Time RT-PCR (qRT-PCR)}

One microlitre of the cDNA above described was used for real-time PCR in a $20 \mu \mathrm{L}$ volume. For each sample three technical replicates were used for PCR amplification. The PCR reaction consisted of $10 \mu \mathrm{L}$ of $\mathrm{iQ}^{\mathrm{m}}$ SYBR Green Supermix 2X (BIO-RAD), which contained buffer, dNTPs and SYBR Green I. Concentrations of the forward and reverse oligodeoxynucleotide primers in the reaction were $500 \mathrm{nM}$ for all the genes of interest.

qRT-PCR experiments were performed using the $i C y$ cler iQ (Bio-Rad Laboratories, Hercules, CA1, USA). Amplification conditions were as follows: initial $95^{\circ} \mathrm{C}$ for $15 \mathrm{~min}$ and 40 cycles of $95^{\circ} \mathrm{C}$ for $30 \mathrm{~s}, 60^{\circ} \mathrm{C}$ for $1 \mathrm{~min}$ and $72^{\circ} \mathrm{C}$ for $1 \mathrm{~min}$ each.

Relative expression analysis was determined by using the 2- $\triangle \Delta \mathrm{CT}$ method [59]; Applied Biosystems User Bulletin No. 2-P/N 4303859). Calculation and statistical analyses were performed by Gene Expression Macro ${ }^{\mathrm{Tw}}$ Version 1.1 (Bio-Rad Laboratories, Hercules, CA, USA). The efficiencies of target and housekeeping genes were determined by qRT-PCR on serial dilutions of RNA template over a 100-fold range [59], with similar results (data not shown). Amplified products were checked by gel electrophoresis and sequencing to verify primer specificity. Relative 
expression of each gene is reported as the number of fold increase of the transcript level at each time point, compared to the lowest transcript level.

As for semiquantitative RT-PCR, GAPDH was used as housekeeping gene.

\section{Estimation of Total starch, Amylose and protein content}

Total starch content of grounded kernels was determined by Megazymes Total Starch Assay Kit (AA/AMG, Megazyme Pty Ltd., Wicklow, Ireland).

Amylose content was estimated by iodometric assay as reported in Chrastil [60] by using starch extracted from mature wheat kernels according to procedure described by Zhao and Sharp [61].

Protein content was determined by the Dumas combustion method, using a Leco FP 428 analyzer (Leco Co., St. Joseph, MI) calibrated with an EDTA standard.

\section{Protein extraction and analysis}

The preparation of starch granules from half seeds and the separation of starch granule bound proteins by SDSPAGE followed the method reported by Zhao and Sharp [61] with some modifications, as in Mohammadkhani et al. [62]. Protein bands were visualized by silver staining.

\section{RVA}

Starch paste viscosity was measured by the rapid visco analyzer (RVA series 4, Newport Scientific, Sidney, Australia). Whole durum wheat flour $(3,87 \mathrm{~g})$ was mixed with $25,13 \mathrm{~mL}$ of $0,2 \%$ silver nitrate in a RVA canister. The starch suspension was, constantly, stirred at $160 \mathrm{rpm}$ and heated from 50 to $95^{\circ} \mathrm{C}$, held at $95^{\circ} \mathrm{C}$ for $4 \mathrm{~min}$ and then cooled to $50^{\circ} \mathrm{C}$ for $4 \mathrm{~min}$. The following variables were recorded in duplicate: peak viscosity (PV), breakdown (BK), trough (TG), final paste viscosity (FV), peak time $(\mathrm{Pt})$, pasting temperature (PT), and setback (SB). Viscosity was expressed in Rapid Visco Unit (RVU).

\section{Mass spectrometry}

Starch was isolated from 5 seeds as described in Zhao and Sharp [61] with same modification. Starch was resuspended in $1000 \mu \mathrm{l}$ extraction buffer (Tris 0,5 M; SDS 10\%, glycerol $50 \%$, sucrose and DTT 1\%) and boiled for $15 \mathrm{~min}$. Gelled starch solution was then cooled at $-20^{\circ} \mathrm{C}$ for 1 hour and centrifuged at $13000 \mathrm{rpm}$ for $10 \mathrm{~min}$. Four volumes of acetone were added to the supernatant that was stored at $-20^{\circ} \mathrm{C}$ overnight. The samples was centrifuged at $4^{\circ} \mathrm{C}$ at $8500 \mathrm{rpm}$ for $40 \mathrm{~min}$; pellet was washed with 2,5 $\mathrm{ml}$ of aceton for three times, and finally air-dried. Precipitated proteins were resuspended in $35 \mu \mathrm{l}$ extraction buffer and loaded on SDS-PAGE ( $\mathrm{T}=10 ; \mathrm{C}=1,28)$, running at $200 \mathrm{~V}$ for $1 \mathrm{~h}$ and 35 minute. Protein bands were visualized by colloidal coomassie CBBG-250 [63], rinsed out with mill-Q water filter, and captured with sterile scalpel. All steps were conducted in sterile atmosphere, making attention to keratin contaminations. The captured bands were placed in a eppendorf and submitted by Mass spectrometry analysis (University of California, Davis, CA, U.S.A). Scaffold (version Scaffold-2.02.01) was used to analyze Tandem MS/MS based peptides and to identify the proteins. Peptide identifications were accepted if they could be established at greater than $95.0 \%$ probability as specified by the Peptide Prophet algorithm [64]. Protein identifications were accepted if they could be established at greater than $99.0 \%$ probability and contained at least two identified peptides. Protein probabilities were assigned by the Protein Prophet algorithm [65].

The proteins were prepared for MS analysis using standard reduction, alkylation, and tryptic digest procedures [66]. Peptides were dried down, then resolubilized in $2 \%$ acetonitrile $/ 0.1 \%$ trifluoroacetic acid for LC-MS/MS analysis.

Digested peptides were analyzed by LC-MS/MS on a LTQ-FT with Waters nano Acuity UPLC. Peptides were separated with a 90 min gradient using a Waters 100 um $\times 100 \mathrm{~mm} 1.7 \mathrm{um} \mathrm{BEH} 130 \mathrm{C} 18$ reversed phase column at $2 \mu \mathrm{l} / \mathrm{min}$. The LTQ-FT was operated with a top 4 method, where the first scan was acquired in the FT at 100,000 resolution and the top 4 ions in each survey scan were selected for low energy CID in the LTQ. Solvent A composition was $0.1 \%$ formic acid, and solvent B $100 \% \mathrm{ACN}$. Peptides were separated at $2 \mu \mathrm{l} / \mathrm{min}$ on the reversedphase column with this gradient: 0 to $7 \%$ Solvent B in 5 minutes, $7-35 \%$ in 65 minutes, $35-70 \%$ in 5.2 minutes, held at $70 \%$ for 0.8 minutes, $70-1 \%$ in 0.2 minutes, with 13.8 minutes to equilibrate between runs.

$\mathrm{X}$ !Tandem was used to search the MS/MS spectra against both the provided database. A parent mass error of up to $10 \mathrm{ppm}$ was allowed for the searches, and a product mass error of 0.4 Daltons. Complete modification of carbamidomethyl was used, as well as the potential modification of methionine oxidation.

\section{Microscopic Analyses of Starch Granules}

Starch granules were extracted from seeds as reported in Zhao and Sharp [61] with some modifications, as in Mohammadkhani et al. [62]. Samples were critical-pointdried in a Balzer's apparatus equipped with a liquid $\mathrm{CO}_{2}$ inlet and metal-shadowed in a gold sputtering unit equipped with an argon inlet. Specimens were examined in a Jeol JSM 5200 scanning electron microscope.

\section{Additional material}

Additional file 1 Segregation data of RNAi transgenic lines. Biochemical analyses have been performed on $\mathrm{PCR}$ positive seeds of $\mathrm{T}_{2}$ plants.

Authors' contributions

FS carried out part of the transformation work, the molecular analyses and drafted the paper with DL and RDO; MJ carried out the biolistic transformation; 
AD collaborated in the Agrobacterium transformation; EB carried out the biochemical analyses; RDO participated to the biolistic transformation; SM has contributed to the proteomic part of the work; HDJ has collaborated with the Agrobacterium transformation and edited the manuscript; DL conceived and coordinated the work. All authors read and approved the final manuscript.

\section{Acknowledgements}

Rothamsted Research receives grant-aided support from the Biotechnology and Biological Sciences Research Council (BBSRC) of the UK.

\section{Author Details}

'University of Tuscia, Department of Agrobiology \& Agrochemistry, Viterbo, Italy and ${ }^{2}$ Rothamsted Research, Department of Plant Science, Harpenden, UK

Received: 17 December 2009 Accepted: 14 July 2010

Published: 14 July 2010

\section{References}

1. Ellis RP, Cochrane MP, Dale MFB, Duffus CM, Lynn A, Morrison IM, Prentice RDM, Swanston JS, Tiller SA: Starch production and industrial use. J SCi Food Agric 1998, 77:289-311.

2. Ball SG, Morell MK: From Bacterial Glycogen to Starch: Understanding the Biogenesis of the Plant Starch Granule. Annu Rev Plant Biol 2003, 54:207-233.

3. Stone B, Morell MK: Carbohydrate. In Wheat: Chemistry and Technology 4th edition. Edited by: Khan K, Shewry PR. AACC International St. Paul MN; 2009:299-362.

4. Stinard PS, Robertson DS, Schnable PS: Genetic isolation, cloning, and analysis of a mutator-induced, dominant antimorph of the maize amylose extender1 locus. Plant Cell 1993, 5:1555-1566.

5. Mizuno K, Kawasaki T, Shimada H, Satoh H, Kobayashi E, Okumura S, Arai Y, Baba T: Alteration of the structural properties of starch components by the lack of an isoform of starch branching enzyme in rice seeds. J Biol Chem 1993, 268:19084-19091.

6. Bhattacharyya MK, Smith AM, Ellis THN, Hedley C, Martin C: The wrinkledseed character of pea described by Mendel is caused by a transposonlike insertion in a gene encoding starch-branching enzyme. Cell 1990, 60:115-122

7. Blauth SL, Yao Y, Klucinec JD, Shannon JC, Thompson DB, Guiltinan MJ: Identification of Mutator insertional mutants of starch-branching enzyme 2a in corn. Plant Physiol 2001, 125:1396-1405.

8. Blauth SL, Kim KN, Klucinec J, Shannon JC, Thompson D, Guiltinan M: Identification of Mutator insertional mutants of starch-branching enzyme 1 (sbe1) in Zea mays L. Plant Mol Biol 2002, 48:287-297.

9. Satoh H, Nishi A, Yamashita K, Takemoto Y, Tanaka Y, Hosaka Y, Sakurai A Fujita N, Nakamura Y: Starch-Branching Enzyme I-Deficient Mutation Specifically Affects the Structure and Properties of Starch in Rice Endosperm. Plant Physiol 2003, 133:1111-1121.

10. Nair RB, Baga M, Scoles GJ, Kartha KK, Chibbar RN: Isolation, characterization and expression analysis of a starch branching enzyme II cDNA from wheat. Plant Sci 1997, 122:153-163.

11. Rahman S, Regina A, Li Z, Mukai Y, Yamamoto M, Kosar-Hashemi B, Abrahams S, Morell MK: Comparison of starch-branching enzyme genes reveals evolutionary relationships among isoforms. Characterization of a gene for starch-branching enzyme lla from the wheat genome donor Aegilops tauschii. Plant Physiol 2001, 125:1314-1324.

12. Regina A, Kosar-Hashemi B, Li Z, Pedler A, Mukai Y, Yamamoto M, Gale K, Sharp PJ, Morell MK, Rahman S: Starch branching enzyme Ilb in wheat is expressed at low levels in the endosperm compared to other cereals and encoded at a non-syntenic locus. Planta 2005, 222:899-909.

13. Gao M, Fisher DK, Kim KN, Shannon JC, Guiltinan MJ: Independent genetic control of maize starch-branching enzymes Ila and IIb Isolation and characterization of a Sbe2a cDNA. Plant Physiol 1997, 114:69-78.

14. Yamanouchi H, Nakamura Y: Organ specificity of isoforms of starch branching enzyme (Q-enzyme) in rice. Plant Cell Physiol 1992, 33:985-991.

15. Regina A, Bird A, Topping D, Bowden S, Freeman J, Barsby T, KosarHashemi B, Li Z, Rahman S, Morell MK: High-amylose wheat generated by RNA interference improves indices of large-bowel health in rats. Proc Natl Acad Sci USA 2006, 103:3546-3551.
16. Englyst HN, Kingman SM, Hudson GJ, Cummings JH: Measurement of resistant starch in vitro and in vivo. Br J Nutr 1996, 75:749-755.

17. Nugent AP: Health properties of resistant starch. Nutr Bull 2005 , 30:27-54.

18. Topping DL, Morell MK, King RA, Li Z, Bird AR, Noakes M: Resistant Starch and Health - Himalaya 292, a Novel Barley Cultivar to Deliver Benefits to Consumers. Starch/Stärke 2003, 55:539-545.

19. Bingham SA, Day NE, Luben R, Ferrari P, Slimani N, Norat T, ClavelChapelon F, Kesse E, Nieters A, Boeing H, Tjønneland A, Overvad K, Martinez C, Dorronsoro M, Gonzalez CA, Key TJ, Trichopoulou A, Naska A, Vineis $\mathrm{P}$, Tumino R, Krogh V, Bueno-de-Mesquita HB, Peeters PH, Berglund G, Hallmans G, Lund E, Skeie G, Kaaks R, Riboli E: Dietary fibre in food and protection against colorectal cancer in the European Prospective. Investigation into Cancer and Nutrition (EPIC): an observational study. Lancet 2003, 361:1496-1501.

20. Lintas C, Cappelloni M, Adorisio S, Clementi A, Del Toma E: Effect of ripening on resistant starch and total sugar in Musa paradisiaca sapientum: glycaemic and insulinaemic responses in normal subjects and NIDDM patients. Eur J Clin Nutr 1995, 49:303-306.

21. Lintas C, Cappeloni M, Bonsmassar L, Clementi A, Del Toma E, Ceccarelli G: Dietary fibre, resistant starch and in vitro digestibility of cereal meals. Glycaemic and insulinaemic responses in NIDDM patients. Eur J Clin Nutr 1995, 49:264-267.

22. Van Hung $P$, Yamamori M, Morita N: Formation of enzyme-resistant starch in bread as affected by high-amylose wheat flour substitutions. Cereal Chem 2005, 82:690-694.

23. Soh HN, Sisson MJ, Turner M: Effect of starch granule size distribution and elevated amylose content on durum dough rheology and spaghetti cooking quality. Cereal Chem 2006, 83:513-519.

24. Yamamori M, Nakamura T, Kuroda A: Variations in the content of starchgranule bound protein among several Japanese cultivars of common wheat (Triticum aestivum L.). Euphytica 1992, 64:215-219.

25. Urbano M, Margiotta B, Colaprico G, Lafiandra D: Waxy protein in diploid, tetraploid and hexaploid wheats. Plant Breeding 2002, 121:1-5.

26. Yamamori M, Fujita S, Hayakawa K, Matsuki J, Yasui T: Genetic elimination of a starch granule protein, SGP-1, of wheat generates an altered starch with apparent high amylose. Theor App/ Genet 2000, 101:21-29.

27. Slade AJ, Fuerstenberg SI, Loeffler D, Steine MN, Facciotti D: A reverse genetic, nontransgenic approach to wheat crop improvement by TILLING. Nat Biotechnol 2005, 23:75-81.

28. Sestili F, Botticella E, Bedo Z, Phillips A, Lafiandra D: Production of novel allelic variation for genes involved in starch biosynthesis through mutagenesis. Mol Breeding 2010, 25:145-154.

29. Fu D, Uauy C, Blechl A, Dubcovsky J: RNA interference for wheat functional gene analysis. Transgenic Res 2007, 16:689-701.

30. Yue SJ, Li H, Li YW, Zhu YF, Guo JK, Liu YJ, Chen Y, Jia X: Generation of transgenic wheat lines with altered expression levels of $1 \mathrm{Dx} 5$ highmolecular weight glutenin subunit by RNA interference. J Cereal SCi 2008, 47:153-161.

31. Travella S, Klimm TE, Keller B: RNA interference-based gene silencing as an efficient tool for functional genomics in hexaploid bread wheat. Plant Physiol 2006, 142:6-20.

32. Garcia-Perez RD, Houdt HV, Depicker A: Spreading of posttranscriptional gene silencing along the target gene promotes systemic silencing. Plant J 2004, 38:594-602

33. McGinnis K, Murphy N, Carlson AR, Akula A, Akula C, Basinger H, Carlson M, Hermanson P, Kovacevic N, McGill MA, Seshadri V, Yoyokie J, Cone K, Kaeppler HF, Kaeppler SM, Springer NM: Assessing the efficiency of RNA interference for maize functional genomics. Plant Physiol 2007, 143:1441-1451.

34. Kerschen A, Napoli CA, Jorgensen RA, Muller AE: Effectiveness of RNA interference in transgenic plants. FEBS Lett 2004, 566:223-228.

35. Shimada T, Otani M, Hamada T, Kim SH: Increase of amylase content of sweetpotato starch by RNA interference of the starch branching enzyme II gene (IbSBEII). Plant Biotechnol 2006, 23:85-90

36. Andersson M, Melander $M$, Pojmark $P$, Larsson $H$, Bulow $L$, Hofvander $P$ : Targeted gene suppression by RNA interference: an efficient method for production of high-amylose potato lines. J Biotechnol 2006, 123:137-148.

37. McClearly BV, Solah V, Gibson TS: Quantitative measurement of total starch in cereal flours and products. J Cereal Sci 1994, 20:51-58. 
38. Yamamori M, Kato M, Yui M, Kawasaki M: Resistant starch and starch pasting properties of a starch synthase lla-deficient wheat with apparent high amylose. Aust J Agric Res 2006, 57:531-535.

39. Juhász R, Salgó A: Pasting behavior of amylose, amylopectin and their mixtures as determined by RVA curves and first derivatives. Starch/ Staerke 2008, 60:70-78.

40. You SG, Kim SM: Molecular Characteristics and Functional Properties of Barley Starches with Varying Amylose Content. J Food Sci Nutr 2003, 10:207-213.

41. Morita N, Maeda T, Miyazaki M, Yamamori M, Miura H, Ohtsuka I: Dough and baking properties of high-amylose and waxy wheat flours. Cereal Chem 2002, 79:491-495.

42. Kosar-Hashemi B, Li Z, Larroque O, Regina A, Yamamori M, Morell MK, Rahman S: Multiple effects of the starch synthase II mutation in developing wheat endosperm. Funct Plant Bio/ 2007, 34:431-438

43. Nakamura Y, Umemoto T, Takahata Y, Komae K, Amano E, Satoh H: Changes in structure of starch and enzyme activities affected by sugary mutations in developing rice endosperm. Physiol Plantarum 1996, 97:491-498.

44. Gao M, Wanat J, Stinard PS, James MG, Myers AM: Characterization of dull1, a maize gene coding for a novel starch synthase. Plant Cell 1998 10:399-412.

45. Stahl Y, Coates S, Bryce JH, Morris PC: Antisense down regulation of the barley limit dextrinase inhibitor modulates starch granule size distribution, starch composition and amylopectin structure. Plant J 2004, 39:599-611.

46. Tetlow IJ, Wait R, Lu Z, Akkasaeng R, Bowsher CG, Esposito S, KosarHashemi B, Morell MK, Emes MJ: Protein phosphorylation in amyloplasts regulates starch branching enzyme activity and protein-protein interactions. Plant Cell 2004, 16:694-708.

47. Tetlow IJ, Beisel KG, Cameron S, Makhmoudova A, Liu F, Bresolin NS, Wait $\mathrm{R}$, Morell MK, Emes MJ: Analysis of protein complexes in wheat amyloplasts reveals functional interactions among starch biosynthetic enzymes. Plant Physiol 2008, 146:1878-1891

48. Hennen-Bierwagen TA, Liu F, Marsh RS, Kim S, Gan Q, Tetlow IJ, Emes MJ, James MG, Myers AM: Starch biosynthetic enzymes from developing maize endosperm associate in multisubunit complexes. Plant Physiol 2008, 146:1892-1908.

49. Hennen-Bierwagen TA, Lin Q, Grimaud F, Planchot V, Keeling PL, James MG, Myers AM: Proteins from Multiple Metabolic Pathways Associate with Starch Biosynthetic Enzymes in High Molecular Weight Complexes: A Model for Regulation of Carbon Allocation in Maize Amyloplasts. Plant Physiol 2009, 149:1541-1559.

50. Grimaud F, Rogniaux H, James MG, Myers AM, Planchot V: Proteome and phosphoproteome analysis of starch granule-associated proteins from normal maize and mutants affected in starch biosynthesis. J Exp Bot 2008, 59:3395-3406.

51. Tosi P, D'Ovidio R, Napier JA, Bekes F, Shewry PR: Expression of epitopetagged LMW glutenin subunits in the starchy endosperm of transgenic wheat and their incorporation into glutenin polymers. Theor App/ Genet 2004, 108:468-476.

52. Christensen AH, Quail PF: Ubiquitin promoter-based vectors for highlevel expressin of selectable and/or screenable marker genes in monocotyledonous plants. Trans Res 1996, 5:213-218.

53. Okubara P, Blechl AE, McCormick SP, Alexander N, Dill-Macky R, Hohn T: Engineering deoxynivalenol metabolism in wheat through the expression of a fungal trichothecene acetyltransferase gene. Theor App/Genet 2002, 106:74-83.

54. Wu X, Doherty A, Jones HD: Efficient and rapid Agrobacteriummediated genetic transformation of durum wheat (Triticum turgidum L. var. durum) using additional virulence genes. Transgenic Res 2008 , 17:425-436

55. Tai TH, Tanksley SD: A rapid and inexpensive method for isolation of total DNA from dehydrated plant tissue. Plant Mol Biol Rep 1990 8:297-303.

56. Laudencia-Chingcuanco DL, Stamova BS, You FM, Lazo GR, Beckles DM, Anderson OD: Transcriptional profiling of wheat caryopsis development using cDNA microarrays. Plant Mol Biol 2006, 63:651-668.

57. Jin YF, Bian TF: Isolation and partial characterization of a novel pollenspecific cDNA with multiple polyadenylation sites from wheat. Acta Biochim Biophys Sin 2004, 36:467-476.
58. Hurkman WJ, McCue KF, Altenbach SB, Korn A, Tanaka CK, Kothari KM, Johnson EL, Bechtel DB, Wilson JD, Anderson OD, DuPont FM: Effect of temperature on expression of genes encoding enzymes for starch biosynthesis in developing wheat endosperm. Plant Sci 2003, 164:873-881.

59. Livak KJ, Schmittgen TD: Analysis of relative gene expression data using real-time quantitative PCR and the $2^{-\Delta \Delta C T}$ method. Methods 2001, 25:402-408

60. Chrastil J: Improved colourimetric determination of amylose in starches or flours. Carbohydr Res 1987, 159:154-158.

61. Zhao XC, Sharp PJ: An improved 1-D SDS-PAGE method for the identification of three bread wheat waxy proteins. J Cereal Sci 1996, 23:191-193.

62. Mohammadkhani A, Stoddard FL, Marshall DR, Uddin MN, Zhao X: Starch extraction and amylose analysis from half seeds. Starch/Stärke 1999, 51:62-66.

63. Neuhoff V, Arold N, Taube D, Ehrhardt W: Improved staining of proteins in polyacrylamide gels including isoelectric focusing gels with clear background at nanogram sensitivity using Coomassie Brilliant Blue G250 and R-250. Electrophoresis 1998, 9:255-262.

64. Keller A, Nesvizhskii Al, Kolker E, Aebersold R: Empirical statistical model to estimate the accuracy of peptide identifications made by MS/MS and database search. Anal Chem 2002, 74:5383-5392.

65. Nesvizhskii Al, Keller A, Kolker E, Aebersold RA: Statistical model for identifying proteins by tandem mass spectrometry. Anal Chem 2003, 75:4646-4658.

66. Rosenfeld J, Capdevielle J, Guillemot JC, Ferrara P: In-gel digestion of proteins for internal sequence analysis after one- or two-dimensional gel electrophoresis. Anal Biochem 1992, 203:173-179.

doi: 10.1186/1471-2229-10-144

Cite this article as: Sestili et al., Increasing the amylose content of durum wheat through silencing of the SBElla genes BMC Plant Biology 2010, 10:144

\section{Submit your next manuscript to BioMed Centra and take full advantage of:}

- Convenient online submission

- Thorough peer review

- No space constraints or color figure charges

- Immediate publication on acceptance

- Inclusion in PubMed, CAS, Scopus and Google Scholar

- Research which is freely available for redistribution 